\title{
The expression of Nanog protein and fibroblast growth factor- inducible molecule 14 in patients with non-small cell lung cancer and their relationship with pathological characteristics and prognosis
}

\author{
Yaqian Wang ${ }^{1}$, Ping Zhou ${ }^{2}$, Cunxiao Cui ${ }^{1}$, Xinxia He ${ }^{1}$, Yali Bian ${ }^{1}$, Xiuzheng Wang ${ }^{3}$ \\ ${ }^{1}$ General Medicine Department, Hengshui People's Hospital, Hengshui, China; ${ }^{2}$ Department of Thoracic Surgery, Hengshui People's Hospital, \\ Hengshui, China; ${ }^{3}$ Tuberculosis Department, The Affiliated Hospital of Hebei University, Baoding, China \\ Contributions: (I) Conception and design: Y Wang, X Wang; (II) Administrative support: P Zhou; (III) Provision of study materials or patients: Y \\ Wang, P Zhou, C Cui, X He, Y Bian; (IV) Collection and assembly of data: All authors; (V) Data analysis and interpretation: C Cui, X He, Y Bian, X \\ Wang; (VI) Manuscript writing: All authors; (VII) Final approval of manuscript: All authors. \\ Correspondence to: Xiuzheng Wang. Affiliated Hospital of Hebei University, No. 648 Dongfeng East Road, Baoding 071000, China. \\ Email: wang18132727795@163.com.
}

Background: This study aimed to explore the expression of Nanog and fibroblast growth factor-inducible molecule 14 (Fn14) in patients with non-small cell lung cancer (NSCLC), and to explore their relationship with pathological characteristics and prognosis.

Methods: The clinical data of 89 patients with NSCLC admitted to this hospital from March 2015 to January 2019 were analyzed. The expression of Nanog and Fn14 in NSCLC tissues and normal tissues ( $5 \mathrm{~cm}$ around the tumor tissue) were analyzed by immunohistochemical staining. The relationship between Nanog and Fn14 expression and the patients' pathological parameters was analyzed. Receiver operating characteristic curve (ROC) and Kaplan-Meier survival curves were drawn to analyze the influence of Nanog and Fn14 expression on prognosis, and logistic regression analysis was used to examine the related factors affecting the 2-year prognostic mortality of patients.

Results: The positive rates of Nanog and Fn14 in the observation group were significantly higher than those in the control group $(\mathrm{P}<0.05)$. The positive expression rates of Nanog and Fn14 were higher in patients with moderate/high differentiation, TNM stage III-IV, and lymph node metastasis $(\mathrm{P}<0.05)$. Among 89 patients with NSCLC, 25 patients died within 2 years of follow-up, with a survival rate of $71.91 \%$. The mortality of patients with positive expression of Nanog and Fn14 was significantly higher than that of patients with negative expression $(\mathrm{P}<0.05)$. The median survival times of patients with negative and positive Nanog expression were $(20.60 \pm 2.71)$ months and $(18.03 \pm 2.11)$ months, respectively. The median survival times of patients with negative and positive Fn14 expression were (19.55 \pm 2.60$)$ months and $(15.65 \pm 2.14)$ months, respectively. The Kaplan-Meier survival curve showed that patients with both negative expression of Nanog and Fn14 had a longer survival time $(\mathrm{P}<0.05)$. Poor differentiation, TNM stage III-IV, lymph node metastasis, positive expression of Nanog, and positive expression of Fn14 were identified as risk factors affecting the prognostic mortality of patients with NSCLC $(\mathrm{P}<0.05)$.

Conclusions: Nanog and Fnl4 are closely related to the occurrence, development, and prognosis of NSCLC. Detection of their expression levels can provide reliable information for the early diagnosis of patients with NSCLC.

Keywords: Non-small cell lung cancer (NSCLC); Nanog protein; factor-inducible molecule 14 (Fn14); pathological features

Submitted Apr 07, 2021. Accepted for publication May 19, 2021.

doi: $10.21037 /$ tcr-21-724

View this article at: http://dx.doi.org/10.21037/tcr-21-724 


\section{Introduction}

Lung cancer is the leading cause of cancer-related deaths in China and worldwide, and its morbidity and mortality rank first among malignant tumor diseases that originate from the bronchial mucosal epithelium (1). It has been reported that non-small cell lung cancer (NSCLC) accounts for about $80-85 \%$ of all lung cancers $(2,3)$. In recent years, with the development of tumor biology, foreign scholars have proposed the "tumor stem cell hypothesis", and believe that the occurrence of NSCLC is closely related to lung cancer stem cells (4).

Previous studies have reported that Nanog, a key protein of embryonic stem cells, is highly expressed in rectal tumor tissues, and can promote the proliferation and metastasis of rectal tumors through epithelial-mesenchymal transition (EMT) and other pathways, which are significantly correlated with patient prognosis (5). Related studies have also reported that the abnormal expression of fibroblast growth factor-inducible molecule 14 (Fn14) is closely related to the occurrence and metastasis of liver cancer, esophageal cancer, breast cancer, lung cancer, and other malignant tumors (6).

There are numerous relevant studies on the correlation between the Nanog protein, Fn14, and NSCLC patients both at home and abroad. However, whether the expression of Nanog and Fn14 can be used as key indicators to reflect the progression of NSCLC and assess prognosis remains unclear. Herein, this study aims to explore the expression of Nanog and Fn14 in patients with NSCLC, and analyze the relationship between these two indicators and the pathological characteristics, as well as the prognosis of patients. We present the following article in accordance with the REMARK reporting checklist (available at http://dx.doi.org/10.21037/tcr-21-724).

\section{Methods}

\section{General information}

The clinical data of patients with NSCLC admitted to Hengshui People's Hospital from March 2015 to January 2019 were sorted and analyzed. The inclusion criteria were as follows: (I) patients meeting the 2002 WHO diagnostic criteria for NSCLC, and diagnosed with NSCLC by postoperative pathological examination (7); (II) patients who received no chemotherapy or radiotherapy within 2 months prior to the study, and were not taking any drugs that affect hormone levels; and (III) postoperative paraffin specimens were well preserved, and the tissue to be tested was sufficient. The exclusion criteria were as follows: (I) patients with other malignant tumors and severe diseases of vital organs; (II) patients with mental disorders or Alzheimer's disease; (III) patients with small cell lung cancer; and (IV) patients with missing clinical or imaging data.

After screening according to the inclusion and exclusion criteria, this study finally included 89 patients with NSCLC as the research objects. Of these patients, 47 were males and 42 were females, aged 52-81 years, with an average age of $(63.65 \pm 5.14)$ years. The course of disease of the included patients ranged from 0.8 to 2.2 years, with an average disease course of $(1.35 \pm 0.33)$ year. The NSCLC tissue specimens of the above patients were selected and set as the observation group $(n=89)$; and normal tissue specimens adjacent to the tumor (within $5 \mathrm{~cm}$ ) were selected as the control group $(n=89)$. All procedures performed in this study involving human participants were in accordance with the Declaration of Helsinki (as revised in 2013). The informed consent was taken from all the patients. This study was approved by the ethics committee of Hengshui People's Hospital (2019-1-026-1).

\section{Nanog protein and Fn14 protein detection methods}

The wax block was sliced serially with a microtome (Leica, Switzerland), with a tissue thickness of $4 \mu \mathrm{m}$, and immunohistochemical staining was performed with antibodies of both Nanog and Fn14, respectively. All specimens were fixed using formaldehyde solution, embedded in paraffin, acidified onto slides, washed with Phosphate Buffer Saline (PBS) buffer sterilized by high temperature, and treated with polylysine smears.

Before developing, Diaminobenzidine tetrahydrochloride (DAB) reagent was prepared as follows: $0.85 \mathrm{~mL}$ of distilled water was added into a sterile test tube. According to the instruments of the DAB kit, $5 \mu \mathrm{L}$ each of the developer $\mathrm{A}, \mathrm{B}$, and $\mathrm{C}$ were then added into the sterile test tube sequentially and mixed enough to be the $\mathrm{DAB}$ developer $(1 \mathrm{~mL})$, which could be effective within 30 minutes away from light. The dyeing time at room temperature was 3-5 min. Subsequently, the tissue specimens, incubated with Nanog and Fn14 antibodies and developed by DAB, were counterstained with hematoxylin, dehydrated with ethanol, transparentized with xylene, and sealed with neutral balsam. Finally, the expression of Nanog and Fn14 was observed under a microscope, and recorded by photograph. The experimental steps were strictly carried out according to the 
Table 1 Expression of Nanog and Fn14 in different tissues

\begin{tabular}{|c|c|c|c|c|c|}
\hline Group & $\mathrm{n}$ & \multicolumn{2}{|c|}{ Nanog expression, $\mathrm{n}(\%)$} & \multicolumn{2}{|c|}{ Fn14 expression, n (\%) } \\
\hline Observation group & 89 & $61(68.54)$ & $28(31.46)$ & $52(58.43)$ & $37(41.57)$ \\
\hline Control group & 89 & $15(16.85)$ & $74(83.15)$ & $26(29.21)$ & $63(70.79)$ \\
\hline$\chi^{2}$ & - & \multicolumn{2}{|c|}{48.587} & \multicolumn{2}{|c|}{15.427} \\
\hline
\end{tabular}

kit instructions.

\section{Reagent kit and main equipment}

The rabbit anti-human Nanog monoclonal antibody was provided by Cell Signaling Technology (USA), and the mouse anti-human Fn14 monoclonal antibody was purchased from eBioscience (USA). The DAB chromogenic reagent and the PV-9000 two-step immunohistochemistry kit were purchased from Beijing Zhongshan Jinqiao Biotechnology (China). Optical microscopes and photomicrograph microscopes were all produced by Olympus (Japan).

\section{Fudgment criteria}

Following development of the color of the samples using the $\mathrm{DAB}$ chromogenic reagent, the staining results were observed under an optical microscope. Nucleus staining was defined as positive staining. The score was independently provided by two pathologists, and the scoring standard was comprehensively evaluated by the staining intensity and the percentage of stained cells (8). Scoring for the proportion of positive cells was as follows: 0 point for $\leq 5 \%, 1$ point for $>5-25 \%, 2$ points for $>25-50 \%, 3$ points for $>50-75 \%$, and 4 points for $>75 \%$. Scoring for intensity was as follows: 0 points for undyed, 1 point for light yellow, 2 points for brown, and 3 points for tan. Staining index $=$ proportion score of positive cells + staining intensity score. Staining index $>3$ points was classified as positive expression, while staining index $\leq 3$ points was classified as negative expression.

\section{Observation indicators}

The expression of Nanog and Fn14 in different tissues was compared, and the relationship between the two indicators and the pathological characteristics of patients with NSCLC was analyzed. The 89 included patients with NSCLC were followed up for 2 years by telephone follow-up or outpatient review, and the deadline for follow-up was January 2021. The follow-up was performed to understand the prognosis of the patients' survival and death, and to record the time of death. Receiver operating characteristic curve (ROC) and Kaplan-Meier survival curves were performed to analyze the impact of Nanog and Fn14 expression on the prognosis of NSCLC patients, and logistic regression analysis was used to clarify the related factors affecting the prognosis of these patients.

\section{Statistical methods}

The SPSS 22.0 software (IBM, New York, USA) was used for statistical analysis. The measurement data were described by the mean \pm standard deviation $\left(\bar{x}_{ \pm s}\right)$, and were analyzed using the $t$-test. The count data was expressed by $\mathrm{n}(\%)$ and analyzed by the chi-squared $\left(\chi^{2}\right)$ test. The ROC curve was drawn, and Kaplan-Meier survival analysis was performed to investigate the effect Nanog and Fn14 expression on the prognosis and survival of patients with NSCLC. The related factors affecting the prognosis of patients were analyzed by logistic regression, and $\mathrm{P}<0.05$ was considered statistically significant.

\section{Results}

\section{Expression of Nanog and Fn14 in different tissues}

The positive rates of Nanog and Fn14 in the observation group were $68.54 \%$ and $58.43 \%$, respectively, which were significantly higher than those in the control group $(\mathrm{P}<0.05$, Table 1 and Figure 1). 

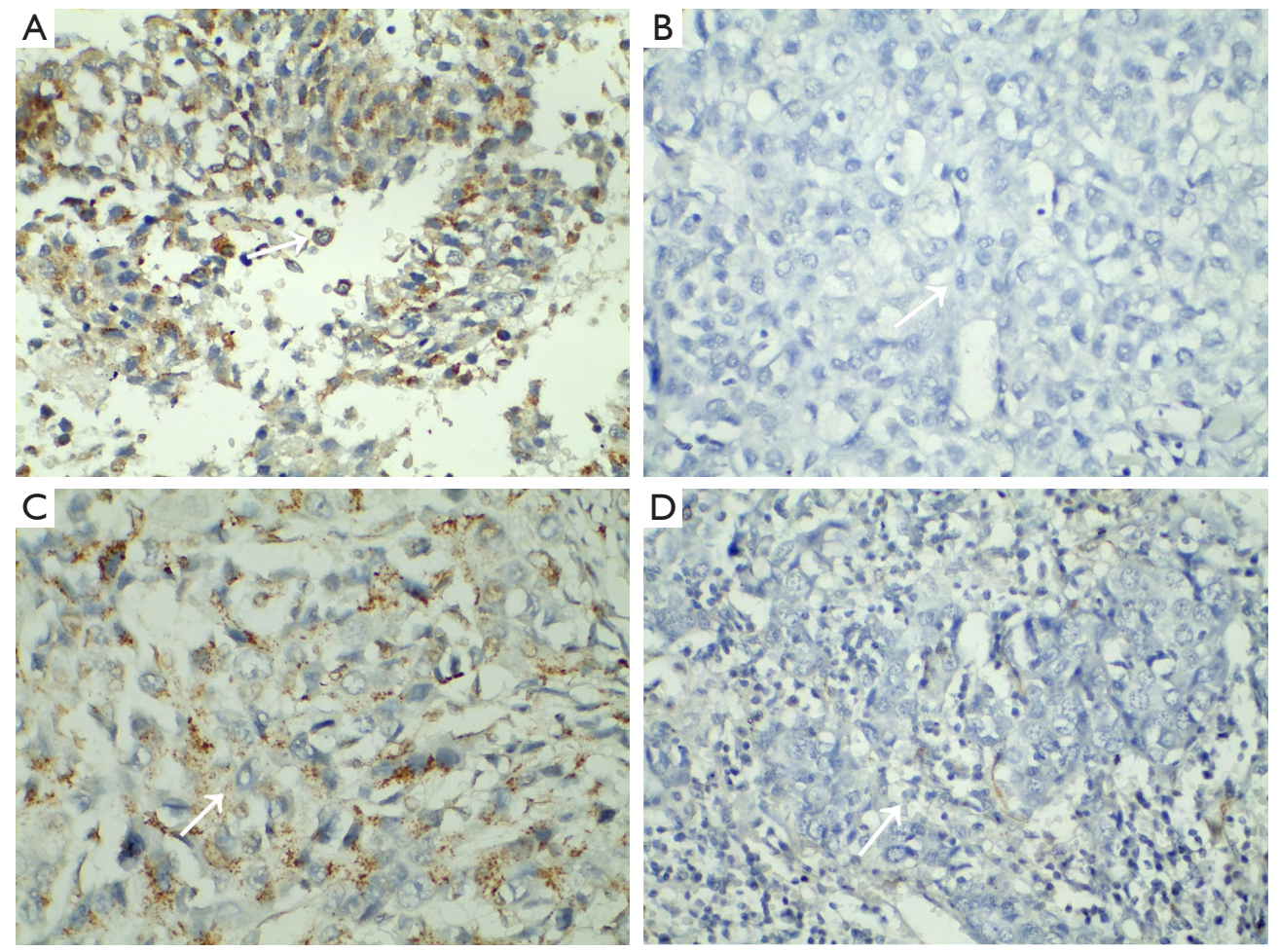

Figure 1 Expression of Nanog and Fn14 by immunohistochemical staining ( $\times 500)$. (A) Positive expression of Nanog in NSCLC tissue; (B) negative expression of Nanog in NSCLC tissue; (C) positive expression of Fn14 in NSCLC tissue; (D) negative expression of Fn14 in NSCLC tissues. NSCLC, non-small cell lung cancer. The white arrows indcate immunohistochemical staining of the nucleus.

\section{The relationship between the expression of Nanog and Fn14 and the pathological parameters of patients with NSCLC}

The expression of Nanog and Fn14 was not related to the gender, age, tumor diameter, and histological type of patients with NSCLC $(\mathrm{P}>0.05)$. The positive expression rates of Nanog and Fn14 were higher in patients with moderate/high differentiation, TNM stage III-IV, and lymph node metastasis $(\mathrm{P}<0.05$, Table 2$)$.

\section{Two-year prognosis of NSCLC patients with different expressions of Nanog and Fn14}

Among the 89 patients with NSCLC included in this study, 25 patients died within 2 years of follow-up, with a survival rate of $71.91 \%$. The mortality of patients with positive expression of Nanog and Fn14 was significantly higher than that of patients with negative expression of Nanog and Fn14 $(\mathrm{P}<0.05$, Table 3).

\section{The relationship between Nanog, Fn14, and the prognosis of NSCLC patients}

The median survival times of patients with negative and positive expressions of Nanog were $(20.60 \pm 2.71)$ months and $(18.03 \pm 2.11)$ months, respectively. The median survival times of patients with negative and positive expressions of Fn14 were $(19.55 \pm 2.60)$ months and $(15.65 \pm 2.14)$ months, respectively. Survival analysis showed that Nanog-negative and Fn14-negative patients exhibited a longer survival time. The Kaplan-Meier survival curves of Nanog-negative and Fn14-negative patients were significantly different from those of Nanog-positive and Fn14-positive patients $(\mathrm{P}<0.05$, Figure 2).

\section{Related risk factors that affect the 2-year prognosis and death of NSCLC patients}

The risk factors affecting the 2-year prognosis of NSCLC patients included the low degree of differentiation, TNM 
Table 2 Relationship between the expression of Nanog and Fn14 and the pathological parameters of patients with NSCLC

\begin{tabular}{|c|c|c|c|c|c|c|c|c|c|c|}
\hline $\begin{array}{l}\text { Pathological } \\
\text { parameter }\end{array}$ & Subgroups & $\begin{array}{l}\text { Case } \\
(\mathrm{n}=89)\end{array}$ & \multicolumn{2}{|c|}{ Nanog expression, n (\%) } & $\chi^{2}$ & $\mathrm{P}$ & \multicolumn{2}{|c|}{ Fn14 expression, n (\%) } & $\chi^{2}$ & $\mathrm{P}$ \\
\hline \multirow[t]{2}{*}{ Gender } & Male & 47 & $30(49.18)$ & $17(60.71)$ & 1.024 & 0.311 & $25(48.08)$ & $22(59.46)$ & 1.124 & 0.289 \\
\hline & Female & 42 & $31(50.82)$ & $11(39.29)$ & & & 27 (51.92) & $15(40.54)$ & & \\
\hline Age (year) & $<60$ & 39 & 25 (40.98) & $14(50.00)$ & 0.007 & 0.934 & $22(42.31)$ & 17 (45.95) & 0.116 & 0.733 \\
\hline \multirow{2}{*}{$\begin{array}{l}\text { Diameter of } \\
\text { tumor }(\mathrm{cm})\end{array}$} & $>5$ & 44 & $31(50.82)$ & $12(42.86)$ & 0.487 & 0.485 & 27 (51.92) & $17(45.94)$ & 0.309 & 0.578 \\
\hline & $\leq 5$ & 45 & $30(49.48)$ & $16(57.14)$ & & & $25(48.08)$ & $20(54.05)$ & & \\
\hline \multirow{2}{*}{$\begin{array}{l}\text { Differentiated } \\
\text { degree }\end{array}$} & Low & 37 & $30(49.48)$ & $7(25.00)$ & 4.620 & 0.032 & $31(59.62)$ & $6(16.22)$ & 16.763 & $<0.001$ \\
\hline & Moderate/high & 52 & $31(50.82)$ & $21(75.00)$ & & & 21 (40.38) & 31 (83.78) & & \\
\hline \multirow{2}{*}{$\begin{array}{l}\text { Lymphatic } \\
\text { metastasis }\end{array}$} & Yes & 50 & $41(67.21)$ & $9(32.14)$ & 9.588 & 0.002 & $39(75.00)$ & $11(29.73)$ & 17.996 & $<0.001$ \\
\hline & No & 39 & $20(32.79)$ & $19(67.86)$ & & & $13(25.00)$ & $26(70.27)$ & & \\
\hline \multirow{2}{*}{$\begin{array}{l}\text { Histological } \\
\text { type }\end{array}$} & Adenocarcinoma & 42 & $29(47.54)$ & $13(46.43)$ & 0.010 & 0.922 & $26(50.00)$ & $16(43.24)$ & 0.396 & 0.529 \\
\hline & $\begin{array}{l}\text { Squamous } \\
\text { carcinoma }\end{array}$ & 47 & $32(52.46)$ & $15(53.57)$ & & & $26(50.00)$ & $21(56.76)$ & & \\
\hline
\end{tabular}

NSCLC, non-small cell lung cancer.

Table 3 Two-year prognosis of NSCLC patients with different expressions of Nanog and Fn14

\begin{tabular}{|c|c|c|c|c|c|c|}
\hline Index & Subgroups & Case & Dead $(n=25), n(\%)$ & Survival ( $\mathrm{n}=64), \mathrm{n}(\%)$ & $\chi^{2}$ & $\mathrm{P}$ \\
\hline Nanog expression & Negative & 28 & $2(8.00)$ & $26(40.63)$ & & \\
\hline \multirow[t]{2}{*}{ Fn14 expression } & Positive & 52 & $20(80.00)$ & $32(50.00)$ & 6.661 & 0.010 \\
\hline & Negative & 37 & $5(20.00)$ & $32(50.00)$ & & \\
\hline
\end{tabular}

NSCLC, non-small cell lung cancer.

stage III-IV, lymph node metastasis, Nanog positive expression, and $\mathrm{F} n 14$ positive expression $(\mathrm{P}<0.05$, Table 4).

\section{Discussion}

During the early stages of NSCLC, there are no typical symptoms. However, as time progresses, the tumor develops further and causes symptoms such as cough, sputum, chest tightness, hemoptysis, weight loss, and other symptoms. The rapid growth of tumors and their characteristic tendency to distant metastasis seriously endangers the life and health of humans. Therefore, searching for biochemical markers is of critical importance to the early detection, diagnosis, and treatment of NSCLC, as well as the assessment of prognosis.

Nanog is a key factor for embryonic stem cells to maintain self-renewal and pluripotency. Osorio et al. (9) reported that Nanog can promote the progression of lung cancer by increasing the properties of tumor stem cells. In recent years, many studies have confirmed that Nanog can increase the malignancy of tumors, leading to an increased risk of prognostic death in patients with malignant tumors (10-12). In this study, the Nanog positive rate of NSCLC tissues was $68.54 \%$, which was significantly higher than that of normal tissues adjacent to the tumor, which is consistent with the results reported in previous studies (13). It has 
A

Survival analysis

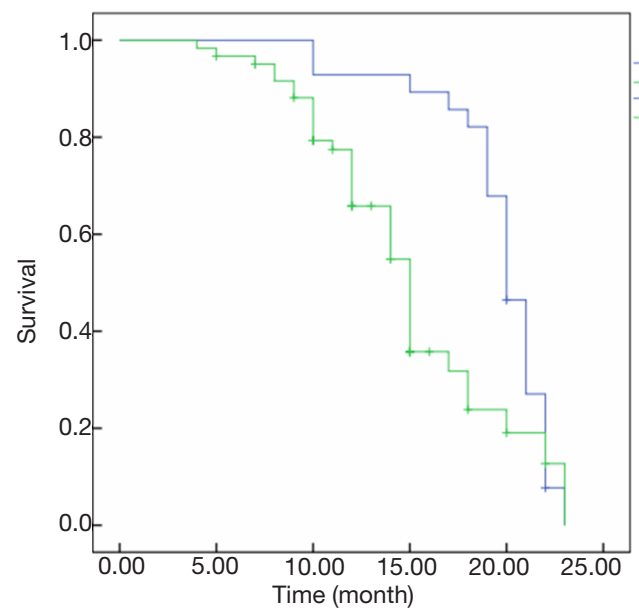

B

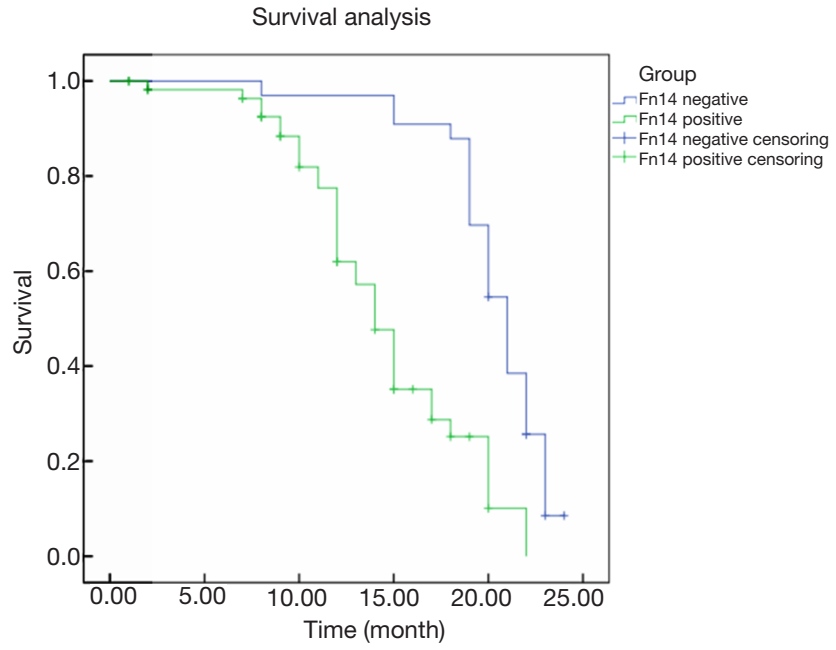

Figure 2 Kaplan-Meier survival curve. (A) Comparison of survival time of patients with positive and negative expression of Nanog; (B) comparison of survival time of patients with positive and negative expression of Fn14.

Table 4 Related risk factors affecting the 2-year prognosis and death of NSCLC patients

\begin{tabular}{|c|c|c|c|c|c|c|}
\hline Index & \multicolumn{3}{|c|}{ Single factor analysis } & \multicolumn{3}{|c|}{ Multiple-factor analysis } \\
\hline Gender: male vs. female & 1.471 & $0.941-2.299$ & 0.688 & - & - & - \\
\hline Age (year): $<60$ vs. $\geq 60$ & 1.265 & $0.365-1.654$ & 0.458 & - & - & - \\
\hline Diameter of tumor $(\mathrm{cm}):>5$ vs. $\leq 5$ & 1.516 & $0.949-2.422$ & 0.632 & - & - & - \\
\hline TNM stage: III-IV vs. I-II & 1.587 & $1.236-1.769$ & 0.014 & 1.358 & $1.158-1.853$ & 0.028 \\
\hline Lymphatic metastasis: yes vs. no & 1.452 & $1.325-1.882$ & 0.019 & 1.425 & $1.307-1.873$ & 0.033 \\
\hline $\begin{array}{l}\text { Histological type: adenocarcinoma vs. } \\
\text { squamous carcinoma }\end{array}$ & 1.251 & $0.124-1.689$ & 0.968 & - & - & - \\
\hline $\begin{array}{l}\text { Fn14: positive expression vs. negative } \\
\text { expression }\end{array}$ & 1.452 & $1.247-1.698$ & 0.013 & 1.339 & $1.124-1.889$ & 0.010 \\
\hline
\end{tabular}

NSCLC, non-small cell lung cancer.

also been reported that the Nanog protein may play an important role in the initial stages of lung cancer occurrence and development (14). However, there are relatively few reports involving a Kaplan-Meier analysis of the expression of Nanog on the prognosis of NSCLC. Lim et al. (15) believed that higher Nanog expression levels was indicative of worse patient prognosis, which can be clearly concluded from pathological characteristics, such as pathological grade, TNM staging, and lymph node metastasis of tumors. The results of this study showed that patients with positive expression of Nanog had characteristics of lower tissue differentiation, TNM stage of III-IV, and a high risk of lymph node metastasis. The 2-year the prognostic mortality rate of patients with positive expression of Nanog was $92.00 \%$, and the survival time was significantly shorter than that of patients with negative expression of 
Nanog, indicating that the prognostic outcome of this study is consistent with the previously reported viewpoints. These results indicate that Nanog is closely related to the progression and prognosis of patients with NSCLC, and can reflect the prognostic survival of these patients. Nanog could be used as a biomarker for the diagnosis of early NSCLC to improve the rate of early diagnosis, and is thus a targeted treatment goal for lung cancer.

Fnl4 is a member of the tumor necrosis factor receptor superfamily. Numerous studies have reported that Fnl4 has a high epidermal size in solid tumors and participates in the regulation of growth, invasion, and metastasis of tumor cells (16-18). Currently, there are few studies on the relationship between Fn14 expression and tumor characteristics in patients with NSCLC. Previous studies have shown that Fnl4 can promote tumor cell migration, extracellular matrix degradation, and invasion, and plays an important role in tumor angiogenesis, as well as tumor growth and metastasis via regulation of the nuclear factor $\mathrm{kB}(\mathrm{NF}-\mathrm{kB})$ signaling pathway $(19,20)$. Our study found that the Fnl4 level was related to the degree of differentiation, TNM staging, and lymph node metastasis in patients with NSCLC, indicating that Fnl4 is involved in the process of tumor invasion and metastasis. The results of our survival analysis showed that NSCLC patients with negative expression of Fnl4 had a longer survival time, suggesting that Fnl4 expression is related to the prognosis of NSCLC patients. After further analysis of the non-conditional multivariate logistic regression model, we found that Nanog and Fnl4 were related risk factors for the prognostic mortality of patients with NSCLC, which reaffirmed the value of Nanog and Fnl4 in the occurrence, development, and prognostic evaluation of NSCLC.

In summary, Nanog and Fnl4 are closely related to the occurrence, development, and prognosis of NSCLC, suggesting that these two indicators may play a certain regulatory role in the formation and development of malignant tumors. However, the sample size included in this study was small and the study duration was short, which makes it difficult to reflect their overall prognostic status. In future research, we will investigate the predictive value of Nanog and Fnl4 on the prognostic mortality of patients with NSCLC in greater depth.

\section{Acknowledgments}

Funding: This work was supported by the Hengshui City Science and Technology Plan Project (2019014088z).

\section{Footnote}

Reporting Checklist: The authors have completed the REMARK reporting checklist. Available at http://dx.doi. org/10.21037/tcr-21-724

Data Sharing Statement: Available at http://dx.doi. org/10.21037/tcr-21-724

Conflicts of Interest: All authors have completed the ICMJE uniform disclosure form (available at http://dx.doi. org/10.21037/tcr-21-724). The authors have no conflicts of interest to declare.

Ethical Statement: The authors are accountable for all aspects of the work in ensuring that questions related to the accuracy or integrity of any part of the work are appropriately investigated and resolved. All procedures performed in this study involving human participants were in accordance with the Declaration of Helsinki (as revised in 2013). The informed consent was taken from all the patients. This study was approved by the ethics committee of Hengshui People's Hospital (2019-1-026-1).

Open Access Statement: This is an Open Access article distributed in accordance with the Creative Commons Attribution-NonCommercial-NoDerivs 4.0 International License (CC BY-NC-ND 4.0), which permits the noncommercial replication and distribution of the article with the strict proviso that no changes or edits are made and the original work is properly cited (including links to both the formal publication through the relevant DOI and the license). See: https://creativecommons.org/licenses/by-nc-nd/4.0/.

\section{References}

1. El-Sherif WT, Sayed SK, Galal SH, et al. Diagnostic Role of RASSF1A and p16INK4a Promoter Gene Hypermethylation in Serum DNA of Lung Cancer Patients: Clinicopathological Significance. Egypt J Immunol 2016;23:1-16.

2. Herbst RS, Morgensztern D, Boshoff C. The biology and management of non-small cell lung cancer. Nature 2018;553:446-54.

3. Horn L, Spigel DR, Vokes EE, et al. Nivolumab Versus Docetaxel in Previously Treated Patients With Advanced Non-Small-Cell Lung Cancer: Two-Year Outcomes From Two Randomized, Open-Label, Phase III Trials 
(CheckMate 017 and CheckMate 057). J Clin Oncol 2017;35:3924-33.

4. Scagliotti GV, Parikh P, von Pawel J, et al. Phase III study comparing cisplatin plus gemcitabine with cisplatin plus pemetrexed in chemotherapy-naive patients with advanced-stage non-small-cell lung cancer. J Clin Oncol 2008;26:3543-51.

5. Costa Y, Ding J, Theunissen TW, et al. NANOGdependent function of TET1 and TET2 in establishment of pluripotency. Nature 2013;495:370-4.

6. Alvarez-Sola G, Uriarte I, Latasa MU, et al. Fibroblast growth factor 15/19 (FGF15/19) protects from dietinduced hepatic steatosis: development of an FGF19-based chimeric molecule to promote fatty liver regeneration. Gut 2017;66:1818-28.

7. Su Z, Dias-Santagata D, Duke M, et al. A platform for rapid detection of multiple oncogenic mutations with relevance to targeted therapy in non-small-cell lung cancer. J Mol Diagn 2011;13:74-84.

8. Yap TA, Macklin-Doherty A, Popat S. Continuing EGFR inhibition beyond progression in advanced non-small cell lung cancer. Eur J Cancer 2017;70:12-21.

9. Osorio JC, Ni A, Chaft JE, et al. Antibody-mediated thyroid dysfunction during T-cell checkpoint blockade in patients with non-small-cell lung cancer. Ann Oncol 2017;28:583-9.

10. Chen CL, Uthaya Kumar DB, Punj V, et al. NANOG Metabolically Reprograms Tumor-Initiating Stemlike Cells through Tumorigenic Changes in Oxidative Phosphorylation and Fatty Acid Metabolism. Cell Metab 2016;23:206-19.

11. de Langen AJ, Jebbink M, Hashemi SMS, et al. Trastuzumab and paclitaxel in patients with EGFR mutated NSCLC that express HER2 after progression on EGFR TKI treatment. Br J Cancer 2018;119:558-64.

12. Lai HH, Li CW, Hong CC, et al. TARBP2-mediated destabilization of Nanog overcomes sorafenib resistance in hepatocellular carcinoma. Mol Oncol 2019;13:928-45.

13. Galetta D, Logroscino AF, Misino A, et al. Neutrophil/ Lymphocyte Ratio in Advanced Non-Small Cell Lung Cancer: Correlation with Prognosis and Response to AntiPD1 Therapy. J Thorac Oncol 2017;12:1329-30.

14. Martinez-Marti A, Felip E, Matito J, et al. Dual MET and ERBB inhibition overcomes intratumor plasticity in osimertinib-resistant-advanced non-small-cell lung cancer (NSCLC). Ann Oncol 2017;28:2451-7.

15. Lim SM, Kim HR, Lee JS, et al. Open-Label, Multicenter, Phase II Study of Ceritinib in Patients With Non-SmallCell Lung Cancer Harboring ROS1 Rearrangement. J Clin Oncol 2017;35:2613-8.

16. Celik E, Semrau R, Baues C, et al. Robot-assisted Extracranial Stereotactic Radiotherapy of Adrenal Metastases in Oligometastatic Non-small Cell Lung Cancer. Anticancer Res 2017;37:5285-91.

17. Katakami N, Hida T, Nokihara H, et al. Phase I/II study of tecemotide as immunotherapy in Japanese patients with unresectable stage III non-small cell lung cancer. Lung Cancer 2017;105:23-30.

18. Lukas RV, Gandhi M, O'Hear C, et al. Safety and efficacy analyses of atezolizumab in advanced non-small cell lung cancer (NSCLC) patients with or without baseline brain metastases. Ann Oncol 2017;28:88-93.

19. Gao SJ, Kim AW, Puchalski JT, et al. Indications for invasive mediastinal staging in patients with early nonsmall cell lung cancer staged with PET-CT. Lung Cancer 2017;109:36-41.

20. Sawa K, Koh Y, Kawaguchi T, et al. PIK3CA mutation as a distinctive genetic feature of non-small cell lung cancer with chronic obstructive pulmonary disease: A comprehensive mutational analysis from a multiinstitutional cohort. Lung Cancer 2017;112:96-101.

(English Language Editor: A. Kassem)
Cite this article as: Wang Y, Zhou P, Cui C, He X, Bian Y, Wang X. The expression of Nanog protein and fibroblast growth factor-inducible molecule 14 in patients with nonsmall cell lung cancer and their relationship with pathological characteristics and prognosis. Transl Cancer Res 2021;10(5):24702477. doi: 10.21037/tcr-21-724 